\title{
Managing adult Fontan patients: where do we stand?
}

\author{
Paul Clift ${ }^{1}$ and David Celermajer ${ }^{2}$
}

Affiliations: ${ }^{1}$ Dept of Cardiology, University Hospital Birmingham, Birmingham, UK. ${ }^{2}$ Dept of Cardiology, Royal Prince Alfred Hospital, Sydney, Australia.

Correspondence: Paul Clift, 1st Floor Nuffield House, Queen Elizabeth Hospital, Birmingham, B15 2TH, UK. E-mail: Paul.Clift@uhb.nhs.uk

ABSTRACT The Fontan operation is performed as a palliative procedure to improve survival in infants born with a functionally univentricular circulation. The success of the operation is demonstrated by a growing adult Fontan population that exists with this unique physiology. Late follow-up has demonstrated expected and unexpected sequelae, and has shown multisystem effects of this circulation. This review discusses the challenges of managing the late complications in terms of understanding this unique physiology and the innovative therapeutic interventions that are being investigated. The challenge remains to maintain quality of life for adult survivors, as well as extending life expectancy.

0 @ERSpublications

Innovative solutions are required to meet the challenges of the Fontan circulation faced in adult life http://ow.ly/XTSm305oH8b

\section{Introduction}

A univentricular circulation describes a congenital heart defect where a biventricular repair is not possible, typically associated with hypoplasia of one of the ventricles and/or atrioventricular valves, and often with other associated features (figure 1). It is rare, with a prevalence of $\sim 1: 10000$ live births [1]. Without intervention in early life, survival to adult life is extremely rare and death in childhood is typical $[2,3]$. In 1971, Francis Fontan and his colleagues described a palliative procedure that now bears his name [4], the principles of which have remained unchanged, although the procedure has evolved and is now performed as a standardised surgical or hybrid surgical procedure in developed healthcare economies across the world. Survival to adult life is now expected, but comes with many challenges for the patient, their family and also for their clinicians [5]. In this paper we describe the unique Fontan physiology and the late effects and management strategies employed to maintain health in this complex condition.

\section{The univentricular heart}

Figure 1 shows three examples of univentricular hearts, in which there is dominance of a ventricle and associated abnormalities. In each case a biventricular circulation is not achievable, and without intervention chronic cyanosis, effort intolerance and volume loading of the circulation ensues, leading to significant early morbidity and mortality. Fontan described the concept of bypassing the subpulmonary ventricle by routing the systemic venous return directly into the pulmonary circulation, thus committing the single ventricle to the systemic circulation, abolishing cyanosis, reducing the volume load on the ventricle and improving effort tolerance; the original "atriopulmonary connection" (APC) operation (figure 2a). The disadvantage of this arrangement was that the atrial mass became a sump, leading to

Editorial comment in Eur Respir Rev 2016; 25: 361-363.

Received: Aug 252016 | Accepted after revision: Oct 132016

Conflict of interest: Disclosures can be found alongside this article at err.ersjournals.com

Provenance: The European Respiratory Review received sponsorship from Actelion Pharmaceuticals Ltd, Allschwil, Switzerland, for the publication of these peer reviewed articles.

Copyright CERS 2016. ERR articles are open access and distributed under the terms of the Creative Commons Attribution Non-Commercial Licence 4.0. 
a)

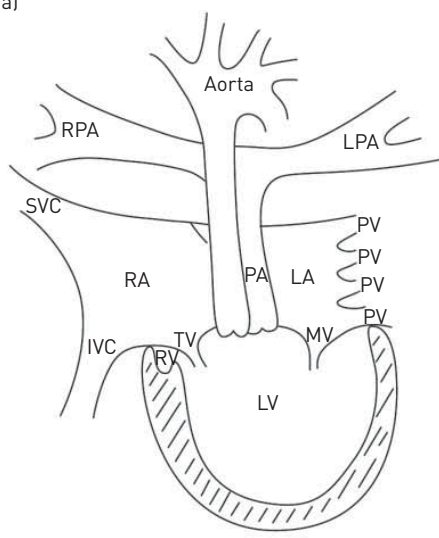

b)

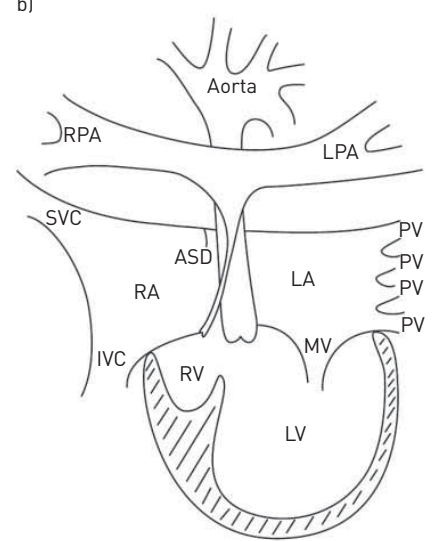

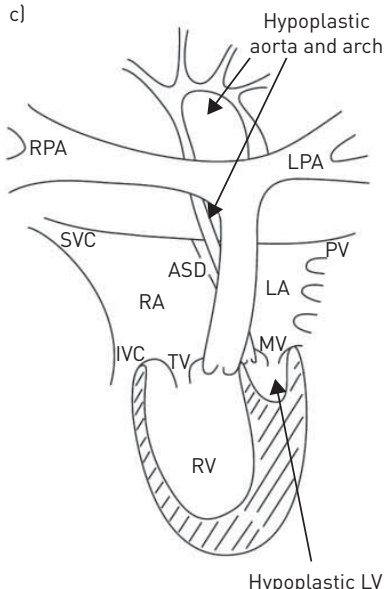

FIGURE 1 Anatomical variations on a univentricular circulation. a) Double inlet left ventricle (LV) with ventriculoarterial discordance and no pulmonary stenosis; b) tricuspid atresia with hypoplastic right ventricle (RV), ventriculoarterial concordance and hypoplastic pulmonary artery (PA); and c) hypoplastic left heart syndrome with atrioventricular and ventriculoarterial concordance, hypoplastic left ventricle, aorta and aortic arch. Many classification systems have been proposed for univentricular hearts. The physician treating adult congenital heart disease needs an understanding of atrial arrangement, atrioventricular valve morphology and the morphology of the dominant ventricle, in addition to the surgical procedures that the patient has undergone, as all of these features will contribute to problems that may be faced in adult life. RPA: right pulmonary artery; LPA: left pulmonary artery; SVC: superior vena cava; RA: right atrium; LA: left atrium; PV: pulmonary vein; IVC: inferior vena cava; TV: tricuspid valve; MV: mitral valve.

energy losses in the circulation and increasing the work of the ventricle, and atrial dilatation predisposed the patient to complex atrial arrhythmias associated with significant morbidity and mortality. Modifications were thus made to optimise the flow characteristics of the Fontan circuit by means of an intra-atrial wall, creating a channel within the atrial mass by which the inferior vena cava flow could be streamed directly to the pulmonary arteries; this is called a lateral tunnel Fontan (figure 2b) [6]. Further modifications were made to remove all atrial tissue from the circulation, believing that this would further improve the flow dynamics and reduce the risk of atrial arrhythmias. This was achieved by means of an extracardiac conduit connecting the inferior vena cava to the pulmonary arteries (figure 2c) [7]. These latter two operations are total cavopulmonary connection (TCPC) forms of Fontan and are the methods employed currently in surgical centres. Initially, adult survivors were mainly APC Fontan patients, but increasing numbers of both forms of TCPC Fontan patients now survive to adult life.

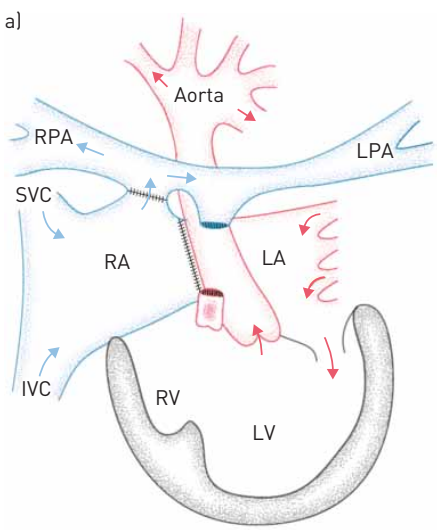

Atriopulmonary connection Fontan

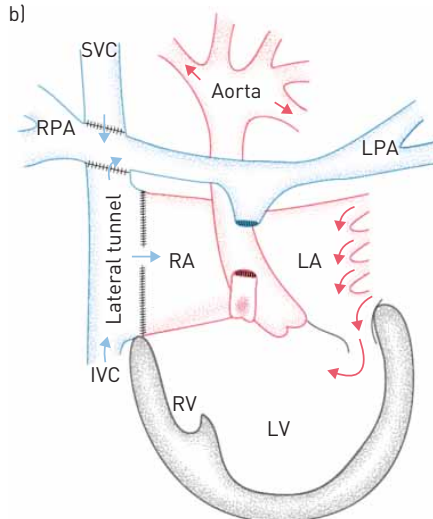

TCPC (lateral tunnel)

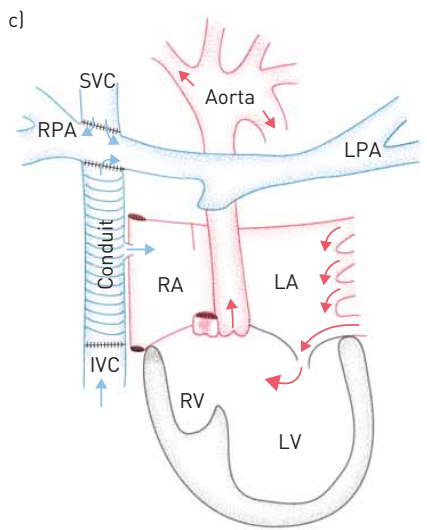

TCPC (extracardiac conduit)

FIGURE 2 Fontan circulation. a) Modified atriopulmonary connection Fontan in which the systemic venous atrium is directly connected to the pulmonary arteries; b) inferior vena cava flow streamed directly to the pulmonary arteries in a right atrium lateral tunnel Fontan; and c) extracardiac conduit connecting the inferior vena cava to the pulmonary arteries. The latter two operations ( $b$ and $c$ ) are forms of total cavopulmonary connection (TCPC) Fontan, and show a fenestration between the total cavopulmonary connection pathway and the right atrium, a common surgical modification performed to relieve pressure in the pathway. RPA: right pulmonary artery; LPA: left pulmonary artery; SVC: superior vena cava; RA: right atrium; LA: left atrium; IVC: inferior vena cava; RV: right ventricle; LV: left ventricle. 
The physiology of the Fontan circulation

Fundamentally, the Fontan circulation differs from the normal parallel pulmonary and systemic circulations by existing as a single circulation in which the pulmonary and systemic circulations run in series. This is powered by the single ventricle and is dependent on a low pulmonary vascular resistance (PVR) to maintain ventricular preload and systemic venous hypertension, driving the transpulmonary blood flow. Figure 3 represents the particular challenges faced at each stage of the Fontan circulation and the current strategies employed to deal with them.

\section{Effects of systemic venous hypertension}

Systemic venous hypertension is necessary to drive blood flow through the pulmonary vasculature, with systemic venous pressure typically $\sim 5 \mathrm{mmHg}$ higher than the pulmonary venous atrial pressure. Pressures in the hepatic veins are higher than normal, with abnormal liver haemodynamics predisposing to late liver complications [8]. Elevated thoracic duct pressures are thought to contribute to prolonged chylous effusions in the early post-Fontan period [9], and later to the development of plastic bronchitis $[10,11]$ and protein-losing enteropathy (PLE) [12, 13].

\section{Hepatic effects}

There is growing recognition of the deleterious effects of systemic venous hypertension on hepatic function and the development of fibrosis, cirrhosis and, worryingly, hepatocellular carcinoma [14-16]. Patients under follow-up routinely undergo liver surveillance including ultrasonographic assessment of fibrosis in order to identify early hepatocellular carcinoma amenable to resection [17], although the optimal type and timing of screening for liver complications remains uncertain. Subclinical hepatic disease can be challenging for patients undergoing cardiac transplantation for Fontan failure and careful multidisciplinary assessment is required [18].

\section{Protein-losing enteropathy}

This complication of the Fontan circulation has challenged physicians for many years [12, 19], diagnosed by a low serum albumin level and the presence of high faecal $\alpha_{1}$-antitrypsin levels [20]. It is a characteristic feature of Fontan failure, leading to peripheral oedema, ascites, pleural effusions, malabsorption and loss of immunoglobulins. There is no reliable therapy, and treatment strategies involve ensuring that the Fontan circuit is free of narrowing, and intervening if necessary. Fontan fenestration has been performed with the acceptance that cyanosis will follow the procedure [21]; latterly, manipulation of the thoracic duct has been proposed [22]. PLE may successfully resolve following cardiac transplantation [23]. Medical therapies include oral budesonide [24, 25], unfractionated heparin [26], spironolactone [27, 28], loperamide [29] and targeted pulmonary vasodilators [30], but none are reliably effective.

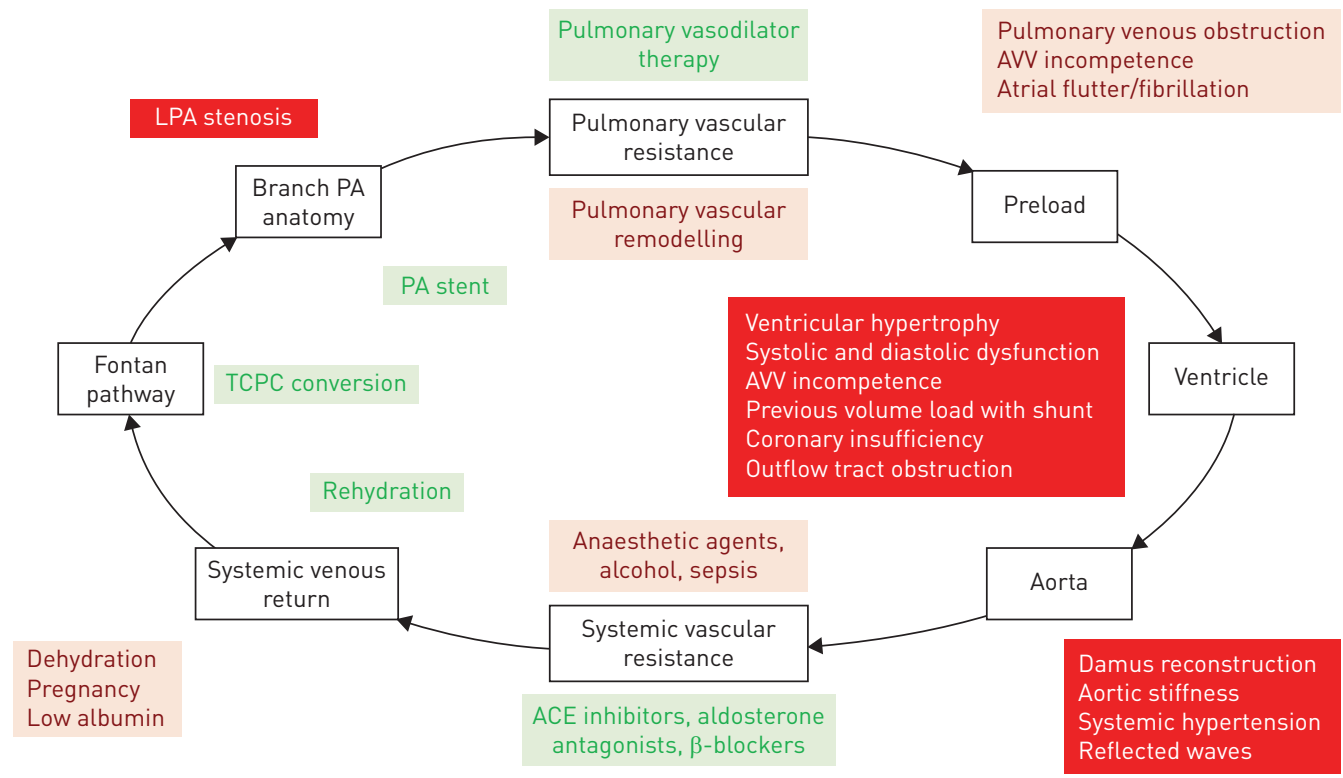

FIGURE 3 Schematic of challenges and management strategies in the Fontan circulation. LPA: left pulmonary artery; PA: pulmonary artery; AVV: atrioventricular valve; ACE: angiotensin-converting enzyme; TCPC: total cavopulmonary connection. 


\section{Atrial stretch and arrhythmias}

Atrial dilatation is commonly seen in the APC Fontan patient. Dilatation and the presence of surgical scars within the atrial mass predispose these patients to atrial arrhythmias, predominantly of the atypical atrial flutter type [31-33]. Scarring within the atrial mass provides the substrate for macro re-entrant tachycardia circuits to form, and the occurrence of this intra-atrial re-entrant tachycardia is a medical emergency in the Fontan patient, in whom it is poorly tolerated. A possible explanation for this is that the atrial arrhythmia increases the pressure in the pulmonary venous atrium leading to a reduction in the pressure gradient down which the pulmonary blood flows. Reduction in pulmonary blood flow further depletes the preload in the single ventricle and leads to a fall in cardiac output. It is a frequent cause of emergency admission in the adult congenital heart disease (ACHD) population, despite Fontan patients being only a small portion of this population. Delay in cardioversion in susceptible patients can lead to death due to circulatory failure.

Many strategies have been employed to reduce the arrhythmia burden, including oral antiarrhythmics such as sotalol and amiodarone. However, the side-effect profile of amiodarone in the young adult makes this less than ideal [34]. A catheter-based ablation strategy has been employed with success in many cases [35-38], but the recurrence rate remains high [38], in part due to the multiple potential substrates within the heart. It is likely that atrial arrhythmias are inevitable in the APC Fontan population [39]. Much has been published about the favourable outcomes in TCPC Fontan, owing to less atrial stretch [40, 41], and with this in mind many centres have performed conversion operations creating a TCPC Fontan and performing cryoablation surgery to remove the substrate for intra-atrial re-entrant tachycardia and improve Fontan flow characteristics [42-46]. However, the conversion operation comes with a significant morbidity and mortality risk [47], and should be considered only in selected cases, having been assessed by an experienced team [48]. Furthermore, TCPC Fontan operations have not completely eliminated the problem of atrial arrhythmia, and pose particular challenges for the interventional electrophysiologist. The use of oral anticoagulants is recommended in all patients who have had an arrhythmia.

\section{Cyanosis and collateral formation}

The maintenance of adequate preload for the single ventricle is a challenge, and one of a number of "autoregulatory" phenomena seen in the Fontan population is the development of veno-venous collateral vessels that pass from the systemic veins to the pulmonary venous circulation [49]. The benefit is to maintain preload and cardiac output, but this comes at a cost of often profound cyanosis that worsens on exertion. Many centres have employed a catheter-based strategy of embolisation of these abnormal vessels $[50,51]$. Whether this impacts on symptoms or survival has not been determined [52], and a further reduction in saturations post-procedure suggests that recurrence rates may be high [51].

\section{Effects of the lack of a subpulmonary ventricle}

The fundamental difference between the Fontan and a normal biventricular circulation is the lack of a subpulmonary ventricle. In all its iterations, the Fontan circulation lacks a synchronised ejection from a subpulmonary ventricle, relying upon changes in intrathoracic pressure during breathing to draw blood through the lungs, and systemic venous hypertension to provide the "header" pressure in the circulation. We have already discussed the vulnerability of this circulation to the effects of atrial arrhythmia, but let us consider its impact on cardiac output and the ability to exercise.

Gewillig et al. [53] addressed this elegantly in a discussion paper on what controls the cardiac output in the Fontan circulation. They explored the areas of contractility, heart rate, afterload, preload and transpulmonary blood flow, before developing a conceptual model of the ageing Fontan circulation (figure $4 \mathrm{a}-\mathrm{d}$ ). Key to the maintenance of cardiac output is the preservation of adequate preload, which depends on a low PVR, with even modest changes in PVR leading to a significant fall in cardiac output and exercise capacity. This hypothesis is difficult to test in routine practice, as standard measurements of PVR by cardiac catheter are technically challenging in the Fontan circulation, but there is evidence of the importance of PVR in the failing Fontan.

Diastolic dysfunction is often quoted as a late effect of the Fontan circulation [54-61], but it remains poorly understood and is likely to be multifactorial. Moreover, measurement of diastolic function using echocardiography may well be inaccurate in a circulation that is, by its nature, preload-depleted. Similarly, chronotropic incompetence may occur due to scar-related sinus node dysfunction [62]. However, atrial pacing does not necessarily augment cardiac output [63], which suggests that the Fontan circulation functions optimally in a narrow range of heart rates. Whether diastolic dysfunction and chronotropic incompetence are likely long-term outcomes of the Fontan circulation or merely a reflection of the physiology remains to be determined. 
a)
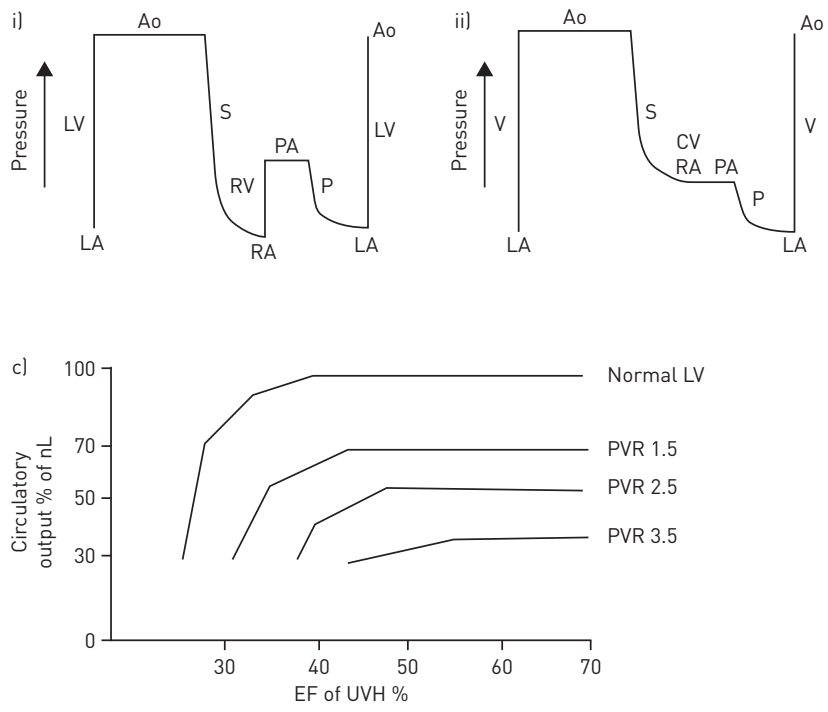
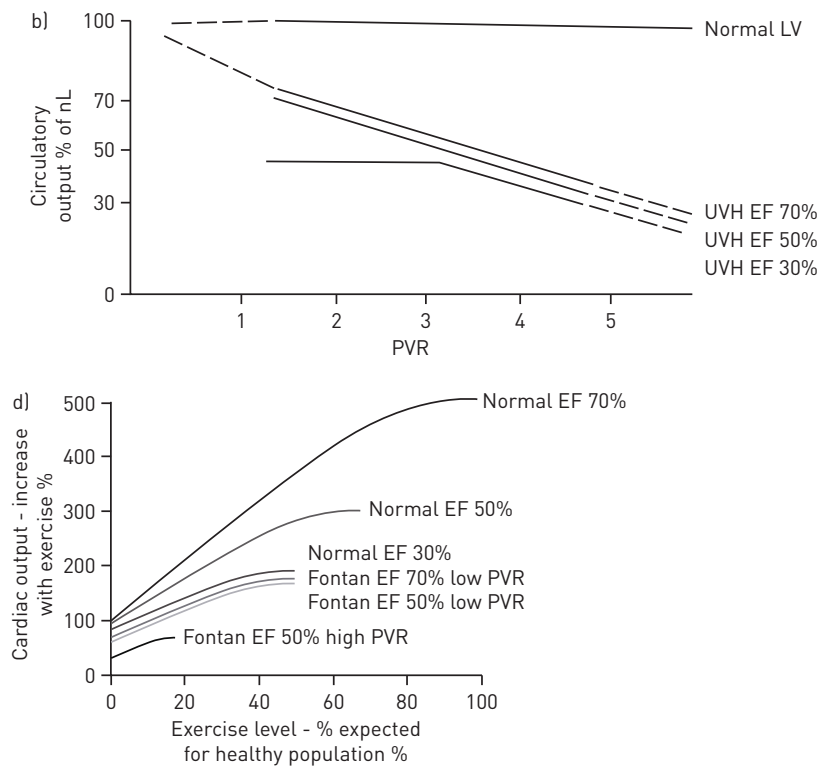

FIGURE 4 Conceptual model of the ageing Fontan circulation. a) Schematic of i) normal and ii) Fontan circulation; b) relationship between circulatory output at rest and pulmonary vascular resistance (PVR) modulated by ventricular function for a normal subject and patients with a univentricular heart (UVH) and depressed ventricular function; c) relationship between circulatory output at rest and ventricular function modulated by PVR for a normal subject and patients with a UVH and depressed ventricular function; d) relationship between cardiac output, PVR and ventricular function during exercise for normal subjects and patients with Fontan circulation. LV: left ventricle; LA: left atrium; Ao: aorta; S: systemic circulation; RV: right ventricle; RA: right atrium; PA: pulmonary artery; P: pulmonary circulation; V: single ventricle; CV: caval veins; EF: ejection fraction. a) Reproduced from [53] with permission from the publisher.

\section{Other organ system involvement}

With increasing length of follow-up, other organ systems appear to be vulnerable to abnormalities. Neurocognitive and developmental issues are of concern [64], and there appears to be an abnormally high incidence of some psychiatric issues, such as anxiety [65]. Bones [66], endocrine systems [67, 68] and lymphatics [69] are also known to be affected in a substantial number of patients with Fontan physiology; the pathogenesis, diagnosis and optimal treatments for these issues are areas of current research activity. Overt renal failure is not routine post-Fontan, but lower-than-normal glomerular filtration rates are found in $\sim 10 \%$ of Fontan patients during long-term follow-up [70].

\section{Pulmonary vascular remodelling}

There is morphological and haemodynamic evidence of pulmonary vascular remodelling and increased PVR. In lung biopsies taken at the time of bidirectional Glenn procedure, patients who subsequently struggled following Fontan completion were demonstrated to have muscularised distal pulmonary arteries; this was a common finding in patients undergoing Fontan completion, despite normal pre-procedural pulmonary haemodynamics [71, 72]. Furthermore, elevated PVR has been demonstrated post-transplantation in patients who have undergone cardiac transplantation for a failing Fontan circulation [73]. Modest elevations in indexed PVR have been found in healthy Fontan patients when studied in detail, with acute lowering of the indexed PVR with inhaled nitric oxide [74]. Therefore, the evidence that pulmonary vascular remodelling exists in these patients is strong, as is evidence that it impacts on the health of these patients. That it can be reduced acutely under experimental conditions is promising, but there is a lack of evidence of a persisting effect beyond the acute reduction, and of an effect that can be achieved with oral pulmonary vasodilators.

\section{Pulmonary vasodilator therapy in the Fontan circulation Phosphodiesterase type-5 inhibitors}

Phosphodiesterase type- 5 inhibitors have been studied both acutely and in case series, with promising preliminary results [75]. In the acute setting, sildenafil has been shown to improve the peak oxygen uptake $\left(V^{\prime} \mathrm{O}_{2}\right)$ in adult Fontan patients [76]. In unselected Fontan populations, sildenafil improves some exercise parameters [75, 77], but in selected failing Fontan patients, sildenafil has been reported to improve symptoms and features of Fontan failure [30, 78-82]. This effect appears dependent on reduction of PVR [83] rather than direct effects on ventricular function [84]. It would appear that "targeted" pulmonary phosphodiesterase type- 5 inhibition may be of benefit to the Fontan patient, although adequately powered clinical trials are still lacking in this regard. 


\section{Endothelin receptor antagonists}

The finding of early pulmonary vascular remodelling in the failing Fontan [71] makes the use of endothelin receptor antagonists (ERAs) an attractive option. In early animal studies, ERAs have been demonstrated to reverse established pulmonary vascular remodelling, in addition to pulmonary vasodilation [85, 86]. Bosentan therapy has been used successfully in many forms of pulmonary arterial hypertension [87]; ambrisentan [88] and macitentan [89] have also shown promise. Increasingly, the focus has been on the combination of therapies targeting the endothelin, cyclic GMP and cyclic AMP pathways [90]. The use of ERAs in the Fontan circulation appears to have an acceptable safety profile [91] and may be effective [92, 93]. The TEMPO study [92] evaluated medium-term bosentan therapy (14 weeks) in a large cohort of adolescent and adult Fontan patients in Scandinavia. Patients were not selected on functional status, and were randomised 1:1 to placebo or bosentan. There was a modest improvement in peak $V^{\prime} \mathrm{O}_{2}$ and an increase in exercise duration with bosentan therapy, and $25 \%$ of the treatment arm improved functional class. The majority of the study population were in functional class I with no perceived limitations. Whether targeting high-risk failing Fontan patients with ERAs, or even combination therapy, is an effective strategy remains to be established and requires larger collaborative randomised clinical trials.

\section{Prostanoids}

Two studies have evaluated the use of inhaled iloprost in the management of Fontan patients. Inhaled iloprost was well tolerated and led to symptomatic improvement and improvement of peak $V^{\prime} \mathrm{O}_{2}$ in limited patients $[94,95]$. The use of prostanoids is not widespread and requires further clinical trial data to recommend its routine use.

There is an emerging evidence base for the use of targeted pulmonary vasodilator therapy in the failing Fontan patient. What remains to be determined is which patients will benefit most, which pulmonary vasodilator is best suited for use in the Fontan circulation and whether combination therapy using currently available targeted pulmonary vasodilators has greater efficacy in Fontan patients than monotherapy. Challenges remain regarding how best to establish a treatment effect and how best to identify patients who may benefit from this therapeutic strategy. While it can be difficult to demonstrate an increase in maximal performance, there may be merit in developing end-points of submaximal exercise performance, such as endurance time [96] or oxygen uptake efficiency slope [97, 98]. How to categorise functional class in patients who do not perceive themselves to be limited is a complex issue. Adaptations to lifestyle in early life is common in the congenital heart disease population and quality of life from a personal perspective is often good [99]. The development of a congenital heart disease specific quality of life score [100] allows investigators to differentiate between physical and psychological aspects of quality of life, and this yields interesting results. Whilst Fontan patients and families report a good quality of life in general [99], when this is examined further, there is a substantial reduction in the physical quality of life while psychosocial quality of life remains good [101, 102]. It is therefore important to assess functional class objectively by means of a structured survey, in order to measure any treatment effect on physical symptoms.

\section{Follow-up of adult Fontan patients}

The process of transition to adult care is by its nature flexible, reflecting the individual circumstances of the patient, their family and their clinical status. Ideally, transition should start no later than 14 years of age and should start in the paediatric setting, building up to transfer to adult care between 16 and 18 years.

Empowerment of the Fontan patient is aided by a detailed discussion of their diagnosis and how it may impact on various aspects of their adult life. This should include a discussion regarding pregnancy and contraception for all female patients, and all should be counselled against the use of recreational drugs and cigarette smoking. Although alcohol is permitted, patients should not binge drink, as this can precipitate arrhythmias. Whether alcohol consumption impacts on the late hepatic function is not established. Body piercing and tattoos are discussed, as is the need for regular dental follow-up. Advice should be given regarding career options, for example, currently the UK armed forces do not accept recruits with any history of congenital heart disease. Discussions also include, where appropriate, sporting and other leisure activities, including whether patients can scuba dive.

The initial adult assessment should include routine cardiovascular examination and the following routine examinations: 12-lead ECG, transthoracic echocardiogram, 24-h ECG monitoring, cardiopulmonary exercise and cardiac magnetic resonance (CMR) imaging in those in whom it is possible. This provides a baseline haemodynamic assessment with which to compare future results.

It is good practice to provide patients with a copy of their 12-lead ECG for them to carry in case they are ever reviewed in an emergency department with palpitations; it is good practice for patients to have copies of all of their healthcare records. Patients should have contact details for the unit, the hospital and clinical nurse specialists. Follow-up is every 12 months, or at short notice if a situation arises. 


\section{Standard medical management}

The nonpulsatile and often turbulent blood flow through the Fontan predisposes the patient to thromboembolism [103]. Subclinical microthrombi in the Fontan pathway could lead to an increase in the PVR, with large occlusive thrombus being a known cause of death [104, 105]. Persistent right-to-left shunts are frequent due to Fontan fenestrations and veno-venous collaterals, with an associated risk of paradoxical embolus. For these reasons many centres routinely anticoagulate their Fontan population, but this remains a subject of debate. There is no evidence in clinical studies of superiority of vitamin $\mathrm{K}$ antagonists over antiplatelet strategies [106-108]; however, patients prescribed neither of these do encounter frequent thrombotic complications [109].

Many Fontan patients are treated with angiotensin-converting enzyme inhibitors, despite there being minimal evidence for their use [110,111], and their use remains controversial [112]. $\beta$-adrenergic blockers and amiodarone are the main therapeutic strategies for secondary prevention of arrhythmias.

Quantitative assessments of performance demonstrate severe limitation in all but the best Fontan patients (rare asymptomatic patients with normal exercise test parameters), but many patients would regard themselves as free of significant effort intolerance. Many have suggested that exercise as a therapeutic strategy could benefit the Fontan patient, due to improved oxygen extraction at the periphery and the additional benefit of the venous muscle pump during exercise. Exercise has been shown to be effective in increasing the peak oxygen consumption of Fontan patients [113-115].

\section{Imaging modalities used in adult Fontan patients}

Transthoracic echocardiography (TTE) remains the most widely available imaging modality in adult cardiology. However, the interpretation of TTE images of the univentricular circulation requires experience and training. Additional training in cardiac morphology of operated and unoperated hearts is of great use.

TTE gives immediate assessment of ventricular function, outflow tract obstruction and atrioventricular valve structure and function. It rarely gives clear images of the Fontan pathway, and is not sufficient to exclude obstruction in the pathway or pulmonary venous pathway obstruction. CMR imaging is now routinely used in the assessment of the Fontan pathway flow, to exclude obstruction and to assess pulmonary venous return [116-119]. In addition, CMR imaging gives very accurate assessment of ventricular function and assessment of branch pulmonary arteries, and, importantly, can exclude re-coarctation or narrowing in the Damus pathway. Transoesophageal echocardiography, in experienced hands, is a useful adjunct to TTE. The pulmonary veins can be readily identified and thrombus within the Fontan circuit can be seen clearly, in addition to obtaining quantitative assessment of the atrioventricular valves.

Cardiac catheterisation can provide both functional and pressure data and indirect estimates of cardiac output by measurement of the mixed venous saturation; however, this is used less in the adult population, where routine assessment largely relies on CMR imaging. Catheter-based interventions are not common in the adult population, but may be required to alleviate obstruction in the Fontan pathway [120], for managing profound cyanosis $[50,121]$ or for stenting of branch pulmonary artery stenosis or venous pathway obstruction [120]. Emergency management of haemoptysis is usually performed in the catheter lab, where identification and embolisation of aorto-bronchial fistulae may be necessary [122].

\section{Assessment of exercise performance}

The assessment of exercise performance in ACHD patients is best achieved using cardiopulmonary exercise testing, which gives accurate, reproducible and quantifiable data on cardiac and respiratory performance. This allows for tracking of performance and assessment of unexpected deterioration. Most Fontan patients have undergone two or three open procedures and may have undergone a thoracotomy. As with other complex lesions, this leads to a restrictive lung defect in many Fontan patients. This finding, in addition to the restrictions in augmentation of the cardiac output on exercise, contribute to a reduction in the measured peak $V^{\prime} \mathrm{O}_{2}$, with average Fontan patients achieving a peak $V^{\prime} \mathrm{O}_{2} \sim 60-70 \%$ that of age-/sex-/size-matched controls [123].

Peak $V^{\prime} \mathrm{O}_{2}$ has been used as an end-point in a number of clinical studies of the Fontan population [92, 93, 124-126]. This has merit in that results are easily quantifiable and reproducible even in the Fontan population [126]. Additional prognostically relevant parameters, such as anaerobic threshold, minute ventilation/carbon dioxide $\left(\mathrm{CO}_{2}\right)$ slope and changes in peak end tidal $\mathrm{CO}_{2}$ are easily quantifiable and could be used to identify patients who may benefit from certain treatment strategies. The haemodynamic response to exercise in Fontan patients is illustrated in figure 5 [127].

\section{Pregnancy and contraception}

A number of centres have recently reported the outcomes of pregnancies in women with a Fontan circulation [128-132], and all of these support earlier published series [133-135]. Both fetal and maternal 
a)

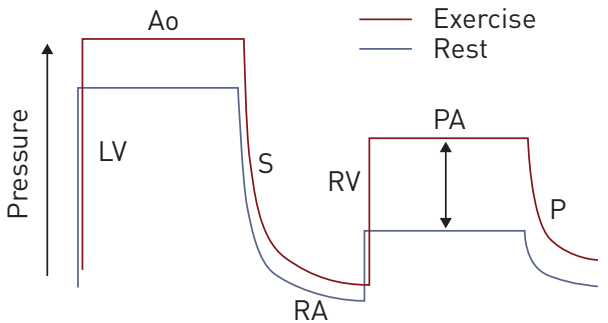

b)

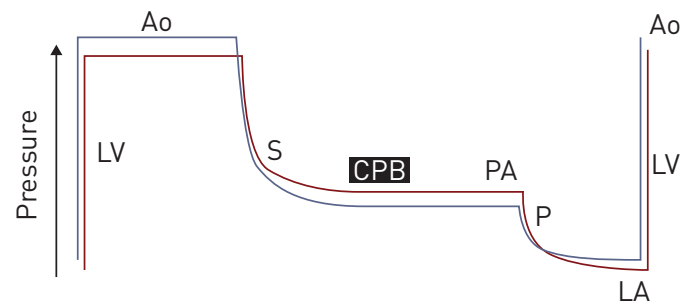

FIGURE 5 Haemodynamic response to exercise in a) normal subjects and b) Fontan patients. In the normal circulation, exercise leads to a rise in aortic (Ao) pressure and a modest rise in systemic (S) venous pressure; right ventricular (RV) pressure increases, as does pulmonary artery (PA) pressure, leading to an increase in pulmonary (P) venous pressure and an increase in preload to the left ventricle (LV). In the Fontan circulation, systemic venous pressure is already high and must remain higher than pulmonary venous pressure to allow transpulmonary blood flow. The result is that, during exercise, there is little if any augmentation of ventricular preload. RA: right atrium; CPB: cavopulmonary bypass; LA: left atrium. Reproduced from [127] with permission from the publisher.

outcomes are generally (but not uniformly) good. Although many pregnancies are carried to term, prematurity is not uncommon and the average gestational age ranges between 31 and 33 weeks [128, 130]. There remains a high risk of fetal loss in the first two trimesters, with miscarriage rates as high as $50 \%$ being typical. Careful pre-pregnancy assessment and counselling is warranted, delivered through dedicated pre-conception counselling. Such clinics inform of the risks of pregnancy and prepare women for the necessary detailed antenatal care that will follow conception. Following counselling, many women choose to defer pregnancy [136], and despite this very high level of specialised care, viable pregnancies occur in the minority of conceptions [136]. Specific measures during antenatal care include management of anticoagulation, with many centres converting warfarin to low molecular weight heparin for the duration of the pregnancy, with the need for weekly anti-Xa monitoring. Angiotensin-converting enzyme inhibition is omitted for the duration of the pregnancy. Delivery planning involves a full multidisciplinary team including an obstetrician, anaesthetist and cardiologist, with a preference for a normal vaginal delivery at term with a short second stage.

The choice of contraception for Fontan patients is relatively straightforward: contraception containing oestrogen is not recommended as this may increase the risk of venous thromboembolism. A number of methods of progestogen-only contraception exist in the form of oral contraception, depot and implantable subdermal contraception. The progestogen intrauterine coil is effective and safe for those who have undergone a pregnancy. Although barrier methods are cardiac-safe they are not as effective as other methods, and those more effective forms of contraception should be employed.

\section{Late effects of the Fontan circulation}

We have already discussed the deleterious effects of systemic venous hypertension. The development of arrhythmias could be thought to be an inevitable part of the Fontan patient's progress [39]. Late mortality occurs, often related to the development of PLE, ventricular dysfunction, thrombotic complications and increasingly life-threatening complications of chronic liver disease [137, 138]. The goal of our management of the adult patient is to preserve symptom-free survival for as long as possible.

This requires a detailed and routine assessment, looking for evidence of deterioration in key areas. Regular review of imaging and exercise performance, monitoring for evidence of liver fibrosis and failure and development of hepatocellular carcinoma are now routine practice in large Fontan centres. This requires the integration of ACHD cardiologists, interventional congenital cardiologists, imaging cardiologists, hepatologists, respiratory physicians, obstetricians and fetal medicine teams, cardiac anaesthetists and intensivists, primary care physicians, clinical nurse specialists, congenital cardiac surgeons and the patients and their families into a multidisciplinary team, dedicated to the identification and management of complications of the Fontan circulation.

Fontan failure may be heralded by a number of symptoms and signs including effort intolerance, increasing arrhythmias, increasing cyanosis, ascites and peripheral oedema and thrombotic complications. The management strategy is one of identification of modifiable conditions and intervention where necessary. Full imaging of the Fontan pathway, ventricle, the outflow tract aorta and arch using TTE and CMR imaging is a first step. In the event of an obstruction being identified, catheter-based interventions may be possible, as previously discussed. Surgical intervention is effective in certain cases. Evaluation of atrioventricular valve regurgitation can be difficult and transoesophageal echocardiography is often 
necessary to understand the mechanism. Although surgery for atrioventricular valve regurgitation can be undertaken, careful consideration of the cases in which this can be attempted needs to be made, as "redo" Fontan surgery is accompanied by high mortality and uncertain outcomes.

The lack of effective management strategies has led to increasing consideration of heart transplantation for the failing Fontan, which in itself comes with a number of challenges. The organ donor shortage in many developed healthcare economies has led to increasingly harsher listing criteria, such that only the most urgent cases are likely to be transplanted. In addition, having multiple previous operations increases the likelihood of the sensitisation of the recipient to the donor organ, further reducing the donor pool [139]. Prolonged donor ischaemic times are more likely, given the need for complex explantation of the recipient's heart. The outcomes of Fontan transplants are less good than non-Fontan ACHD transplants, but despite higher early mortality, long-term survival is better in the ACHD population than the non-ACHD population.

Patients with preserved ventricular function and reduced albumin levels do less well than those whose indication for transplant is primarily pump failure [140]. The presence of liver disease presents an additional challenge and requires a collaborative approach with hepatologists in the pretransplant assessment and the early postoperative phase [18]. It remains the case that the majority of failing Fontan patients do not receive a heart transplant [141].

The reality of lack of organ availability and uncertainty over suitability for transplantation has led to the concept of mechanical support for the failing Fontan. While specific Fontan mechanical support strategies are being considered [142-148], centres have inserted ventricular assist devices in a number of failing paediatric Fontan patients, providing a successful bridge to heart transplantation [149-152]. Whether a total artificial heart strategy could be a long-term solution in this population remains to be established.

\section{Conclusion}

The Fontan circulation is in effect an alternative physiology that has challenged the assumptions of physicians. Terms such as chronotropic incompetence and diastolic dysfunction are in effect descriptions of the autoregulatory effects of the "normal" Fontan circulation; this challenges physicians to understand this novel physiology and to develop novel management strategies when they encounter what appears to be inevitable deterioration in adult life. Collaborative clinical trials are required in large populations of symptomatic Fontan patients to determine the best diagnostic and treatment strategies. Longitudinal data collection will define the natural history of the condition and will allow us to inform patients and families. Presently, our adult Fontan population are pioneers for their paediatric Fontan counterparts. We hope that by investigating our failing adult Fontan patients we can increase the life expectancy and quality of life of future generations of Fontan patients.

\section{References}

1 Qu Y, Liu X, Zhuang J, et al. Incidence of congenital heart disease: the 9-year experience of the Guangdong registry of congenital heart disease, China. PLoS One 2016; 11: e0159257.

2 Moodie DS, Ritter DG, Tajik AH, et al. Long-term follow-up after palliative operation for univentricular heart. Am J Cardiol 1984; 53: 1648-1651.

3 Moodie DS, Ritter DG, Tajik AJ, et al. Long-term follow-up in the unoperated univentricular heart. Am J Cardiol 1984; 53: 1124-1128.

Fontan F, Baudet E. Surgical repair of tricuspid atresia. Thorax 1971; 26: 240-248.

Aboulhosn J, Child JS. The adult with a Fontan operation. Curr Cardiol Rep 2007; 9: 331-335.

de Leval MR, Kilner P, Gewillig $\mathrm{M}$, et al. Total cavopulmonary connection: a logical alternative to atriopulmonary connection for complex Fontan operations. Experimental studies and early clinical experience. J Thorac Cardiovasc Surg 1988; 96: 682-695.

7 Marcelletti C, Corno A, Giannico S, et al. Inferior vena cava-pulmonary artery extracardiac conduit. A new form of right heart bypass. J Thorac Cardiovasc Surg 1990; 100: 228-232.

8 Hsia TY, Khambadkone S, Deanfield JE, et al. Subdiaphragmatic venous hemodynamics in the Fontan circulation. J Thorac Cardiovasc Surg 2001; 121: 436-447.

9 Akbari Asbagh P, Navabi Shirazi MA, Soleimani A, et al. Incidence and etiology of chylothorax after congenital heart surgery in children. J Tehran Heart Cent 2014; 9: 59-63.

10 Shah SS, Drinkwater DC, Christian KG. Plastic bronchitis: is thoracic duct ligation a real surgical option? Ann Thorac Surg 2006; 81: 2281-2283.

11 Hraška V. Decompression of thoracic duct: new approach for the treatment of failing Fontan. Ann Thorac Surg 2013; 96: 709-711.

12 Hess J, Kruizinga K, Bijleveld CM, et al. Protein-losing enteropathy after Fontan operation. J Thorac Cardiovasc Surg 1984; 88: 606-609.

13 Meadows J, Gauvreau K, Jenkins K. Lymphatic obstruction and protein-losing enteropathy in patients with congenital heart disease. Congenit Heart Dis 2008; 3: 269-276.

14 Kiesewetter CH, Sheron N, Vettukattill JJ, et al. Hepatic changes in the failing Fontan circulation. Heart 2007; 93: 579-584.

15 Kendall TJ, Stedman B, Hacking N, et al. Hepatic fibrosis and cirrhosis in the Fontan circulation: a detailed morphological study. J Clin Pathol 2008; 61: 504-508.

16 Saliba T, Dorkhom S, O'Reilly EM, et al. Hepatocellular carcinoma in two patients with cardiac cirrhosis. Eur J Gastroenterol Hepatol 2010; 22: 889-891. 
17 Kwon S, Scovel L, Yeh M, et al. Surgical management of hepatocellular carcinoma after Fontan procedure J Gastrointest Oncol 2015; 6: E55-E60.

18 Greenway SC, Crossland DS, Hudson M, et al. Fontan-associated liver disease: implications for heart transplantation. J Heart Lung Transplant 2016; 35: 26-33.

19 Crupi G, Locatelli G, Tiraboschi R, et al. Protein-losing enteropathy after Fontan operation for tricuspid atresia (imperforate tricuspid valve). Thorac Cardiovasc Surg 1980; 28: 359-363.

20 Thorne SA, Hooper J, Kemp M, et al. Gastro-intestinal protein loss in late survivors of Fontan surgery and other congenital heart disease. Eur Heart J 1998; 19: 514-520.

21 Satomi G, Yasukochi S, Harada Y, et al. Effect of percutaneous fenestration of the atrial septum on protein-losing enteropathy after the Fontan operation. Heart 1996; 76: 90-91.

22 António M, Gordo A, Pereira C, et al. Thoracic duct decompression for protein-losing enteropathy in failing Fontan circulation. Ann Thorac Surg 2016; 101: 2370-2373.

23 Gamba A, Merlo M, Fiocchi R, et al. Heart transplantation in patients with previous Fontan operations. J Thorac Cardiovasc Surg 2004; 127: 555-562.

24 Schumacher KR, Cools M, Goldstein BH, et al. Oral budesonide treatment for protein-losing enteropathy in Fontan-palliated patients. Pediatr Cardiol 2011; 32: 966-971.

25 Thacker D, Patel A, Dodds K, et al. Use of oral budesonide in the management of protein-losing enteropathy after the Fontan operation. Ann Thorac Surg 2010; 89: 837-842.

26 Bhagirath KM, Tam JW. Resolution of protein-losing enteropathy with low-molecular weight heparin in an adult patient with Fontan palliation. Ann Thorac Surg 2007; 84: 2110-2112.

27 Ringel RE, Peddy SB. Effect of high-dose spironolactone on protein-losing enteropathy in patients with Fontan palliation of complex congenital heart disease. Am J Cardiol 2003; 91: 1031-1032.

28 Okano S, Sugimoto M, Takase M, et al. Effectiveness of high-dose spironolactone therapy in a patient with recurrent protein-losing enteropathy after the Fontan procedure. Intern Med 2016; 55: 1611-1614.

29 Windram JD, Clift PF, Speakman J, et al. An unusual treatment for protein losing enteropathy. Congenit Heart Dis 2011; 6: 253-256.

30 Uzun $\mathrm{O}$, Wong JK, Bhole V, et al. Resolution of protein-losing enteropathy and normalization of mesenteric Doppler flow with sildenafil after Fontan. Ann Thorac Surg 2006; 82: e39-e40.

31 Balaji S, Case CL, Sade RM, et al. Arrhythmias and electrocardiographic changes after the hemi-Fontan procedure. Am J Cardiol 1994; 73: 828-829.

32 Fishberger SB, Wernovsky G, Gentles TL, et al. Factors that influence the development of atrial flutter after the Fontan operation. J Thorac Cardiovasc Surg 1997; 113: 80-86.

$33 \mathrm{Li} \mathrm{W}$, Somerville J. Atrial flutter in grown-up congenital heart $(\mathrm{GUCH})$ patients. Clinical characteristics of affected population. Int J Cardiol 2000; 75: 129-137.

34 Thorne SA, Barnes I, Cullinan P, et al. Amiodarone-associated thyroid dysfunction: risk factors in adults with congenital heart disease. Circulation 1999; 100: 149-154.

35 Kalman JM, VanHare GF, Olgin JE, et al. Ablation of "incisional" reentrant atrial tachycardia complicating surgery for congenital heart disease. Use of entrainment to define a critical isthmus of conduction. Circulation 1996; 93: 502-512.

36 Weipert J, Noebauer C, Schreiber C, et al. Occurrence and management of atrial arrhythmia after long-term Fontan circulation. J Thorac Cardiovasc Surg 2004; 127: 457-464.

37 de Groot NM, Lukac P, Blom NA, et al. Long-term outcome of ablative therapy of postoperative supraventricular tachycardias in patients with univentricular heart: a European multicenter study. Circ Arrhythm Electrophysiol 2009; 2: 242-248.

38 Yap SC, Harris L, Silversides CK, et al. Outcome of intra-atrial re-entrant tachycardia catheter ablation in adults with congenital heart disease: negative impact of age and complex atrial surgery. J Am Coll Cardiol 2010; 56: 1589-1596.

39 Quinton E, Nightingale P, Hudsmith L, et al. Prevalence of atrial tachyarrhythmia in adults after Fontan operation. Heart 2015; 101: 1672-1677.

40 Balaji S, Gewillig M, Bull C, et al. Arrhythmias after the Fontan procedure. Comparison of total cavopulmonary connection and atriopulmonary connection. Circulation 1991; 84: Suppl. 5, iiil62-iiil67.

41 Laschinger JC, Ringel RE, Brenner JI, et al. The extracardiac total cavopulmonary connection for definitive conversion to the Fontan circulation: summary of early experience and results. J Card Surg 1993; 8: 524-533.

42 Kreutzer J, Keane JF, Lock JE, et al. Conversion of modified Fontan procedure to lateral atrial tunnel cavopulmonary anastomosis. J Thorac Cardiovasc Surg 1996; 111: 1169-1176.

43 Ninan M, Myers JL. Conversion of the atriopulmonary Fontan connection to a total cavopulmonary connection. Semin Thorac Cardiovasc Surg Pediatr Card Surg Annu 1998; 1: 23-30.

44 van Son JA, Mohr FW, Hambsch J, et al. Conversion of atriopulmonary or lateral atrial tunnel cavopulmonary anastomosis to extracardiac conduit Fontan modification. Eur J Cardiothorac Surg 1999; 15: 150-157.

45 Mavroudis C, Backer CL, Deal BJ, et al. Total cavopulmonary conversion and maze procedure for patients with failure of the Fontan operation. J Thorac Cardiovasc Surg 2001; 122: 863-871.

46 Mavroudis C, Deal BJ, Backer CL. The beneficial effects of total cavopulmonary conversion and arrhythmia surgery for the failed Fontan. Semin Thorac Cardiovasc Surg Pediatr Card Surg Annu 2002; 5: 12-24.

47 Poh CL, Cochrane A, Galati JC, et al. Ten-year outcomes of Fontan conversion in Australia and New Zealand demonstrate the superiority of a strategy of early conversion. Eur J Cardiothorac Surg 2016; 49: 530-535.

48 Mavroudis C, Deal BJ. Fontan conversion: literature review and lessons learned over 20 years. World J Pediatr Congenit Heart Surg 2016; 7: 192-198.

49 Heinemann M, Breuer J, Steger V, et al. Incidence and impact of systemic venous collateral development after Glenn and Fontan procedures. Thorac Cardiovasc Surg 2001; 49: 172-178.

50 Sugiyama $\mathrm{H}$, Yoo SJ, Williams W, et al. Characterization and treatment of systemic venous to pulmonary venous collaterals seen after the Fontan operation. Cardiol Young 2003; 13: 424-430.

51 Lluri G, Levi DS, Aboulhosn J. Systemic to pulmonary venous collaterals in adults with single ventricle physiology after cavopulmonary palliation. Int J Cardiol 2015; 189: 159-163.

52 Poterucha JT, Johnson JN, Taggart NW, et al. Embolization of veno-venous collaterals after the Fontan operation is associated with decreased survival. Congenit Heart Dis 2015; 10: E230-E236. 
Gewillig M, Brown SC, Eyskens B, et al. The Fontan circulation: who controls cardiac output? Interact Cardiovasc Thorac Surg 2010; 10: 428-433.

Kimball TR, Witt SA, Khoury PR, et al. Automated echocardiographic analysis of systemic ventricular performance in hypoplastic left heart syndrome. J Am Soc Echocardiogr 1996; 9: 629-636.

Marino BS. Outcomes after the Fontan procedure. Curr Opin Pediatr 2002; 14: 620-626.

Border WL, Syed AU, Michelfelder EC, et al. Impaired systemic ventricular relaxation affects postoperative short-term outcome in Fontan patients. J Thorac Cardiovasc Surg 2003; 126: 1760-1764.

Vitarelli A, Conde Y, Cimino E, et al. Quantitative assessment of systolic and diastolic ventricular function with tissue Doppler imaging after Fontan type of operation. Int J Cardiol 2005; 102: 61-69.

Margossian R, Schwartz ML, Prakash A, et al. Comparison of echocardiographic and cardiac magnetic resonance imaging measurements of functional single ventricular volumes, mass, and ejection fraction (from the Pediatric Heart Network Fontan Cross-Sectional Study). Am J Cardiol 2009; 104: 419-428.

Menon SC, Gray R, Tani LY. Evaluation of ventricular filling pressures and ventricular function by Doppler echocardiography in patients with functional single ventricle: correlation with simultaneous cardiac catheterization. J Am Soc Echocardiogr 2011; 24: 1220-1225.

Tomkiewicz-Pajak L, Podolec P, Drabik L, et al. Single ventricle function and exercise tolerance in adult patients after Fontan operation. Acta Cardiol 2014; 69: 155-160.

Averin K, Hirsch R, Seckeler MD, et al. Diagnosis of occult diastolic dysfunction late after the Fontan procedure using a rapid volume expansion technique. Heart 2016; 102: 1109-1114.

Bae EJ, Lee JY, Noh CI, et al. Sinus node dysfunction after Fontan modifications - influence of surgical method. Int J Cardiol 2003; 88: 285-291.

Barber G, Di Sessa T, Child JS, et al. Hemodynamic responses to isolated increments in heart rate by atrial pacing after a Fontan procedure. Am Heart J 1988; 115: 837-841.

McCrindle BW, Williams RV, Mitchell PD, et al. Relationship of patient and medical characteristics to health status in children and adolescents after the Fontan procedure. Circulation 2006; 113: 1123-1129.

Bordin G, Padalino MA, Perentaler S, et al. Clinical profile and quality of life of adult patients after the Fontan procedure. Pediatr Cardiol 2015; 36: 1261-1269.

Avitabile CM, Goldberg DJ, Zemel BS, et al. Deficits in bone density and structure in children and young adults following Fontan palliation. Bone 2015; 77: 12-16.

Holler F, Hannes T, Germund I, et al. Low serum 25-hydroxyvitamin D levels and secondary hyperparathyroidism in Fontan patients. Cardiol Young 2016; 26: 876-884.

Mainwaring RD, Lamberti JJ, Carter TL Jr, et al. Reduction in triiodothyronine levels following modified Fontan procedure. J Card Surg. 1994; 9: 322-331.

Rychik J, Goldberg D, Rand E, et al. End-organ consequences of the Fontan operation: liver fibrosis, protein-losing enteropathy and plastic bronchitis. Cardiol Young 2013; 23: 831-840.

Sharma S, Ruebner RL, Furth SL, et al. Assessment of kidney function in survivors following Fontan palliation. Congenit Heart Dis 2016 [In press DOI: 10.1111/chd.12358].

Lévy M, Danel C, Tamisier D, et al. Histomorphometric analysis of pulmonary vessels in single ventricle for better selection of patients for the Fontan operation. J Thorac Cardiovasc Surg 2002; 123: 263-270.

Maeda K, Yamaki S, Kado H, et al. Reevaluation of histomorphometric analysis of lung tissue in decision making for better patient selection for Fontan-type operations. Ann Thorac Surg 2004; 78: 1371-1381.

Mitchell MB, Campbell DN, Ivy D, et al. Evidence of pulmonary vascular disease after heart transplantation for Fontan circulation failure. J Thorac Cardiovasc Surg 2004; 128: 693-702.

Khambadkone S, Li J, de Leval MR, et al. Basal pulmonary vascular resistance and nitric oxide responsiveness late after Fontan-type operation. Circulation 2003; 107: 3204-3208.

Goldberg DJ, French B, McBride MG, et al. Impact of oral sildenafil on exercise performance in children and young adults after the Fontan operation: a randomized, double-blind, placebo-controlled, crossover trial. Circulation 2011; 123: 1185-1193.

Giardini A, Balducci A, Specchia S, et al. Effect of sildenafil on haemodynamic response to exercise and exercise capacity in Fontan patients. Eur Heart J 2008; 29: 1681-1687.

Goldberg DJ, French B, Szwast AL, et al. Impact of sildenafil on echocardiographic indices of myocardial performance after the Fontan operation. Pediatr Cardiol 2012; 33: 689-696.

Do P, Randhawa I, Chin T, et al. Successful management of plastic bronchitis in a child post Fontan: case report and literature review. Lung 2012; 190: 463-468.

Haseyama K, Satomi G, Yasukochi S, et al. Pulmonary vasodilation therapy with sildenafil citrate in a patient with plastic bronchitis after the Fontan procedure for hypoplastic left heart syndrome. J Thorac Cardiovasc Surg 2006; 132: 1232-1233.

Morchi GS, Ivy DD, Duster MC, et al. Sildenafil increases systemic saturation and reduces pulmonary artery pressure in patients with failing Fontan physiology. Congenit Heart Dis 2009; 4: 107-111.

Reinhardt Z, Uzun O, Bhole V, et al. Sildenafil in the management of the failing Fontan circulation. Cardiol Young 2010; 20: 522-525.

Van De Bruaene A, La Gerche A, Claessen G, et al. Sildenafil improves exercise hemodynamics in Fontan patients. Circ Cardiovasc Imaging 2014; 7: 265-273.

Mori H, Park IS, Yamagishi $\mathrm{H}$, et al. Sildenafil reduces pulmonary vascular resistance in single ventricular physiology. Int J Cardiol 2016; 221: 122-127.

Butts RJ, Chowdhury SM, Baker GH, et al. Effect of sildenafil on pressure-volume loop measures of ventricular function in Fontan patients. Pediatr Cardiol 2016; 37: 184-191.

Chen SJ, Chen YF, Opgenorth TJ, et al. The orally active nonpeptide endothelin A-receptor antagonist A-127722 prevents and reverses hypoxia-induced pulmonary hypertension and pulmonary vascular remodeling in Sprague-Dawley rats. J Cardiovasc Pharmacol 1997; 29: 713-725.

DiCarlo VS, Chen SJ, Meng QC, et al. ETA-receptor antagonist prevents and reverses chronic hypoxia-induced pulmonary hypertension in rat. Am J Physiol 1995; 269: L690-L697.

Liu C, Cheng J. Endothelin receptor antagonists for pulmonary arterial hypertension. Cochrane Database Syst Rev 2005; 3: CD004434. 
Peacock AJ, Zamboni W, Vizza CD. Ambrisentan for the treatment of adults with pulmonary arterial hypertension: a review. Curr Med Res Opin 2015; 31: 1793-1807.

89 Clarke M, Walter C, Agarwal R, et al. Macitentan (Opsumit) for the treatment of pulmonary arterial hypertension. Expert Rev Clin Pharmacol 2014; 7: 415-421.

90 Buckley MS, Staib RL, Wicks LM. Combination therapy in the management of pulmonary arterial hypertension. Int J Clin Pract Suppl 2013; 179: 13-23.

91 Bowater SE, Weaver RA, Thorne SA, et al. The safety and effects of bosentan in patients with a Fontan circulation. Congenit Heart Dis 2012; 7: 243-249.

92 Hebert A, Mikkelsen UR, Thilen U, et al. Bosentan improves exercise capacity in adolescents and adults after Fontan operation: the TEMPO (Treatment with Endothelin Receptor Antagonist in Fontan Patients, a Randomized, Placebo-Controlled, Double-Blind Study Measuring Peak Oxygen Consumption) study. Circulation 2014; 130: 2021-2030.

93 Cedars AM, Saef J, Peterson LR, et al. Effect of Ambrisentan on exercise capacity in adult patients after the Fontan procedure. Am J Cardiol 2016; 117: 1524-1532.

94 Kim YH, Chae MH, Choi DY. Inhaled iloprost for the treatment of patient with Fontan circulation. Korean J Pediatr 2014; 57: 461-463.

95 Rhodes J, Ubeda-Tikkanen A, Clair M, et al. Effect of inhaled iloprost on the exercise function of Fontan patients: a demonstration of concept. Int J Cardiol 2013; 168: 2435-2440.

96 O'Donnell DE, Sciurba F, Celli B, et al. Effect of fluticasone propionate/salmeterol on lung hyperinflation and exercise endurance in COPD. Chest 2006; 130: 647-656.

97 Chen CA, Chen SY, Chiu HH, et al. Prognostic value of submaximal exercise data for cardiac morbidity in Fontan patients. Med Sci Sports Exerc 2014; 46: 10-15.

98 Bongers BC, Hulzebos HJ, Blank AC, et al. The oxygen uptake efficiency slope in children with congenital heart disease: construct and group validity. Eur J Cardiovasc Prev Rehabil. 2011; 18: 384-392.

99 Mahle WT, Clancy RR, Moss EM, et al. Neurodevelopmental outcome and lifestyle assessment in school-aged and adolescent children with hypoplastic left heart syndrome. Pediatrics 2000; 105: 1082-1089.

100 Marino BS, Tomlinson RS, Wernovsky G, et al. Validation of the pediatric cardiac quality of life inventory. Pediatrics 2010; 126: 498-508.

101 Idorn L, Jensen AS, Juul K, et al. Quality of life and cognitive function in Fontan patients, a population-based study. Int J Cardiol 2013; 168: 3230-3235.

102 Uzark K, Zak V, Shrader P, et al. Assessment of quality of life in young patients with single ventricle after the Fontan operation. J Pediatr 2016; 170: 166-172.e1.

103 Balling G, Vogt M, Kaemmerer H, et al. Intracardiac thrombus formation after the Fontan operation. $J$ Thorac Cardiovasc Surg 2000; 119: 745-752.

104 Tsang W, Johansson B, Salehian O, et al. Intracardiac thrombus in adults with the Fontan circulation. Cardiol Young 2007; 17: 646-651.

105 Khairy P, Fernandes SM, Mayer JE Jr, et al. Long-term survival, modes of death, and predictors of mortality in patients with Fontan surgery. Circulation 2008; 117: 85-92.

106 Jacobs ML, Pourmoghadam KK, Geary EM, et al. Fontan's operation: is aspirin enough? Is coumadin too much? Ann Thorac Surg 2002; 73: 64-68.

107 Jacobs ML, Pelletier GJ, Pourmoghadam KK, et al. Protocols associated with no mortality in 100 consecutive Fontan procedures. Eur J Cardiothorac Surg 2008; 33: 626-632.

108 Monagle $\mathrm{P}$, Cochrane A, Roberts R, et al. A multicenter, randomized trial comparing heparin/warfarin and acetylsalicylic acid as primary thromboprophylaxis for 2 years after the Fontan procedure in children. $J$ Am Coll Cardiol 2011; 58: 645-651.

109 Potter BJ, Leong-Sit P, Fernandes SM, et al. Effect of aspirin and warfarin therapy on thromboembolic events in patients with univentricular hearts and Fontan palliation. Int J Cardiol 2013; 168: 3940-3943.

110 Kouatli AA, Garcia JA, Zellers TM, et al. Enalapril does not enhance exercise capacity in patients after Fontan procedure. Circulation 1997; 96: 1507-1512.

111 Heragu N, Mahony L. Is captopril useful in decreasing pleural drainage in children after modified Fontan operation? Am J Cardiol 1999; 84: 1109-1112.

112 Wilson TG, Iyengar AJ, Winlaw DS, et al. Use of ACE inhibitors in Fontan: rational or irrational? Int J Cardiol 2016; 210: 95-99.

113 Opocher F, Varnier M, Sanders SP, et al. Effects of aerobic exercise training in children after the Fontan operation. Am J Cardiol 2005; 95: 150-152.

114 Brassard P, Bédard E, Jobin J, et al. Exercise capacity and impact of exercise training in patients after a Fontan procedure: a review. Can J Cardiol 2006; 22: 489-495.

115 Brassard P, Poirier P, Martin J, et al. Impact of exercise training on muscle function and ergoreflex in Fontan patients: a pilot study. Int J Cardiol 2006; 107: 85-94.

116 Hjortdal VE, Christensen TD, Larsen SH, et al. Caval blood flow during supine exercise in normal and Fontan patients. Ann Thorac Surg 2008; 85: 599-603.

117 Takawira F, Ayer JG, Onikul E, et al. Evaluation of the extracardiac conduit modification of the Fontan operation for thrombus formation using magnetic resonance imaging. Heart Lung Circ 2008; 17: 407-410.

118 Fogel MA. Cardiac magnetic resonance of single ventricles. J Cardiovasc Magn Reson 2006; 8: 661-670.

119 Fogel MA, Hubbard A, Weinberg PM. A simplified approach for assessment of intracardiac baffles and extracardiac conduits in congenital heart surgery with two- and three-dimensional magnetic resonance imaging. Am Heart J 2001; 142: 1028-1036.

120 Ovroutski S, Ewert P, Alexi-Meskishvili V, et al. Dilatation and stenting of the Fontan pathway: impact of the stenosis treatment on chronic ascites. J Interv Cardiol 2008; 21: 38-43.

121 Kaulitz R, Ziemer G, Paul T, et al. Fontan-type procedures: residual lesions and late interventions. Ann Thorac Surg 2002; 74: 778-785.

122 Bédard E, Lopez S, Perron J, et al. Life-threatening hemoptysis following the Fontan procedure. Can J Cardiol 2008; 24: 145-147. 

congenital heart disease. Relation to activities of daily life - single centre experience and review of published data. Eur Heart J 2012; 33: 1386-1396.

124 Bansal M, Fiutem JJ, Hill JA, et al. Oxygen pulse kinetics in Fontan patients during treadmill ramp protocol cardiopulmonary exercise testing. Pediatr Cardiol 2012; 33: 1301-1306.

125 Fernandes SM, Alexander ME, Graham DA, et al. Exercise testing identifies patients at increased risk for morbidity and mortality following Fontan surgery. Congenit Heart Dis 2011; 6: 294-303.

126 Fernandes SM, McElhinney DB, Khairy P, et al. Serial cardiopulmonary exercise testing in patients with previous Fontan surgery. Pediatr Cardiol 2010; 31: 175-180.

127 La Gerche A, Gewillig M. what limits cardiac performance during exercise in normal subjects and in healthy Fontan patients? Int J Pediatr 2010; 2010: 791291.

Zentner D, Kotevski A, King I, et al. Fertility and pregnancy in the Fontan population. Int J Cardiol 2016; 208: 97-101.

Kim SY, Cho S, Choi E, et al. Pregnancy and delivery in functional single ventricle patient; successful long-term outcome after right ventricle exclusion and Fontan operation. Korean Circ J 2016; 46: 111-114.

Pundi KN, Pundi K, Johnson JN, et al. Contraception practices and pregnancy outcome in patients after Fontan operation. Congenit Heart Dis 2016; 11: 63-70.

131 Gouton M, Nizard J, Patel M, et al. Maternal and fetal outcomes of pregnancy with Fontan circulation: a multicentric observational study. Int J Cardiol 2015; 187: 84-89.

132 Chugh R. Management of pregnancy in women with repaired CHD or after the Fontan procedure. Curr Treat Options Cardiovasc Med 2013; 15: 646-662.

133 Canobbio MM, Mair DD, van der Velde M, et al. Pregnancy outcomes after the Fontan repair. J Am Coll Cardiol 1996; 28: 763-767.

134 Drenthen W, Pieper PG, Roos-Hesselink JW, et al. Pregnancy and delivery in women after Fontan palliation Heart 2006; 92: 1290-1294.

135 Hoare JV, Radford D. Pregnancy after Fontan repair of complex congenital heart disease. Aust NZ J Obstet Gynaecol 2001; 41: 464-468.

136 Cauldwell M, Von Klemperer K, Uebing A, et al. A cohort study of women with a Fontan circulation undergoing preconception counselling. Heart 2016; 102: 534-540.

137 Ohuchi H. Adult patients with Fontan circulation: what we know and how to manage adults with Fontan circulation? J Cardiol 2016; 68: 181-189.

138 Rychik J. The relentless effects of the Fontan paradox. Semin Thorac Cardiovasc Surg Pediatr Card Surg Annu 2016; 19: 37-43.

139 Hosseinpour AR, Cullen S, Tsang VT. Transplantation for adults with congenital heart disease. Eur J Cardiothorac Surg 2006; 30: 508-514.

140 Murtuza B, Hermuzi A, Crossland DS, et al. Impact of mode of failure and end-organ dysfunction on the survival of adult Fontan patients undergoing cardiac transplantation. Eur J Cardiothorac Surg 2016 [In press DOI: $10.1093 /$ ejcts/ezw243].

141 Shi WY, Yong MS, McGiffin DC, et al. Heart transplantation in Fontan patients across Australia and New Zealand. Heart 2016; 102: 1120-1126.

142 Haggerty CM, Fynn-Thompson F, McElhinney DB, et al. Experimental and numeric investigation of Impella pumps as cavopulmonary assistance for a failing Fontan. J Thorac Cardiovasc Surg 2012; 144: 563-569.

143 Rodefeld MD, Coats B, Fisher T, et al. Cavopulmonary assist for the univentricular Fontan circulation: von Kármán viscous impeller pump. J Thorac Cardiovasc Surg 2010; 140: 529-536.

144 Wei X, Sanchez PG, Liu Y, et al. Mechanical circulatory support of a univentricular Fontan circulation with a continuous axial-flow pump in a piglet model. ASAIO J 2015; 61: 196-201.

145 Zhu J, Kato H, Fu YY, et al. Cavopulmonary support with a microaxial pump for the failing Fontan physiology. ASAIO J 2015; 61: 49-54.

146 Acheampong B, Johnson JN, Stulak JM, et al. Postcardiotomy ECMO support after high-risk operations in adult congenital heart disease. Congenit Heart Dis 2016 [In press DOI: 10.1111/chd.12396].

147 Boni L, Sasaki T, Ferrier WT, et al. Challenges in longer-term mechanical support of Fontan circulation in sheep. ASAIO J 2012; 58: 60-64.

148 Riemer RK, Amir G, Reichenbach SH, et al. Mechanical support of total cavopulmonary connection with an axial flow pump. J Thorac Cardiovasc Surg 2005; 130: 351-354.

149 Calvaruso DF, Ocello S, Salviato N, et al. Implantation of a Berlin heart as single ventricle by-pass on Fontan circulation in univentricular heart failure. ASAIO J 2007; 53: e1-e2.

150 Cardarelli MG, Salim M, Love J, et al. Berlin heart as a bridge to recovery for a failing Fontan. Ann Thorac Surg 2009; 87: 943-946.

151 Halaweish I, Ohye RG, Si MS. Berlin heart ventricular assist device as a long-term bridge to transplantation in a Fontan patient with failing single ventricle. Pediatr Transplant 2015; 19: E193-E195.

152 Nathan M, Baird C, Fynn-Thompson F, et al. Successful implantation of a Berlin heart biventricular assist device in a failing single ventricle. J Thorac Cardiovasc Surg 2006; 131: 1407-1408. 